\title{
Design of a Blade Antenna Embedded in Low-Cost Dielectric Substrate
}

\author{
Waleska F. Silva, I. Bianchi and Tiago P. Santos \\ Laboratory of Antennas and Propagation - LAP, Technological Institute of Aeronautics - ITA, Pr. Mal. Eduardo \\ Gomes, 50 12228-900 São José dos Campos - SP, Brazil, freirewals@gmail.com, bianchi@ita.br, \\ tiagopst@gmail.com
}

\begin{abstract}
A design of a blade antenna embedded in low-cost dielectric substrate (FR4) and operating at $4.97 \mathrm{GHz}$ is the subject of this paper. The antenna design is accomplished using parametric analysis in the $\mathrm{HFSS}^{T M}$ software, where the antenna dimensions are changed and it is observed how the changes affect figures-of-merit like input impedance, reflection coefficient and radiation patterns. The antenna prototype is presented, as well as, a comparison between experimental and theoretical results.
\end{abstract}

Index Terms - antenna, blade, monopoles, embedded

\section{INTRODUCTION}

One of the most installed antenna on aircraft is the monopole [1]. Although cylindrical monopoles are easy to manufacture, they have narrow bandwidth [2], whereas planar monopoles provide more bandwidth and emerge as option to overcome the cylindrical monopole limitation [3].

The blade antenna is classified as wide bandwidth planar monopole and presents aerodynamic features for aeronautic application [1]. However, antennas on aircraft are exposed to climate variations, that creates a need to protect the radiator element with some structure less interfering in the electromagnetic waves [4]. This structure is known as radome.

In this work, the radiator element is presented embedded in the material FR4, which serves as radome. Considering that radiator element geometry can be designed in different shapes, the use of a radome impedes to figure out what is the exact radiator geometry. Hence, it is a designer responsibility uses predefine topologies as starting point for a blade design. Based on that, the proposed antenna started with predefined shapes presented in [6,7] and it was modified to get it operating at $4.97 \mathrm{GHz}$.

The optimized antenna dimensions were achieved through the parametric assessment on the project variables, and how those variables influence on the radiation and electrical characteristics of the antenna. The proposed antenna shall operate on the TCAS (Traffic Collision Avoidance System): bandwidth $960 \mathrm{MHz}-1220 \mathrm{MHz}$ with input impedance of $50 \Omega$ [5]. With the dimensions optimized a prototype was manufactured and electromagnetic measurements were conducted on the prototype and with it installed on metallic cylinder. The cylinder represents an aircraft airframe.

Considering the available resource of the laboratory, a frequency scaling process was adopted to 
conduct the prototype measurements, where the electrical length of an airframe radius it was represented on the metallic cylinder radius. Therefore, it was possible design a blade antenna operating at $4.97 \mathrm{GHz}(4.38-5.56 \mathrm{GHz})$. Since the aircraft comprises of large structure, the conventional method FEM (Finite Element Method), available on $\mathrm{HFSS}^{\mathrm{TM}}$, becomes inefficient, due to amount of time, computer processing and memory spent in the simulation. Thus, the antenna analysis on cylinder was accomplished by a combination of MoM (Method of Moments) and FEM, known as hybrid method (FEM-MoM) [8 - 10].

In the next sections, it will be presented the antenna geometry, parametric studies and the prototype with its theoretical and experimental results.

\section{ANTENNA GEOMETRY}

The Fig. 1 shows the first blade antenna proposed. The lengths $\mathrm{x}_{\mathrm{a}}$ and $\mathrm{x}_{\mathrm{b}}$, gap, probe position $(p)$, slot width $\left(\mathrm{a}_{\mathrm{c}}\right)$, radome presence and ground plan dimensions were changed in order to observe the effects on the input impedance, reflection coefficient magnitude, impedance bandwidth (-10dB return loss condition) and radiation pattern. All three slots have the same width $\left(\mathrm{a}_{\mathrm{c}}\right)$.

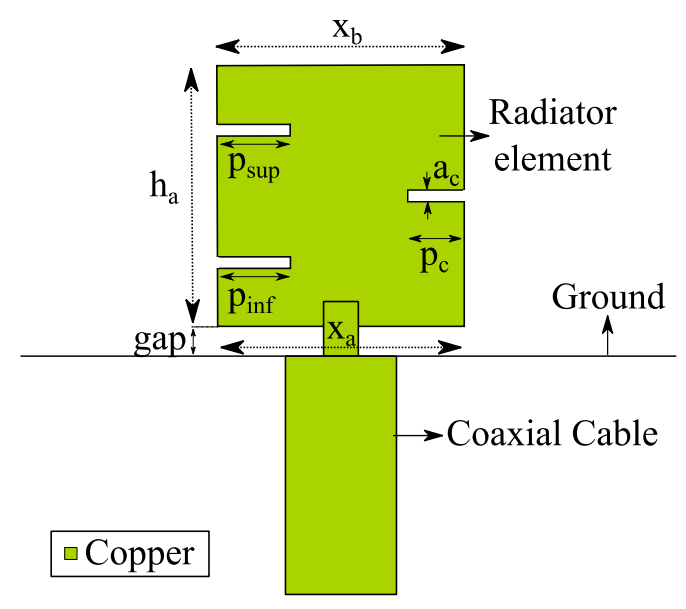

Fig. 1. Initial blade antenna.

After the parametric assessments on the blade antenna proposed on Fig. 1, it was reached in the model of Fig. 2, where it's also presented the radiator element embedded in dielectric substrate and both on a square ground plan. This dielectric is constituted by two FR4 layers $\left(\varepsilon_{\mathrm{r}}=4.4 ; \tan \delta=0.02\right)$, with thickness $h=3.2 \mathrm{~mm}$. On one layer it was printed the radiator element, while the other servers as protection (radome). 

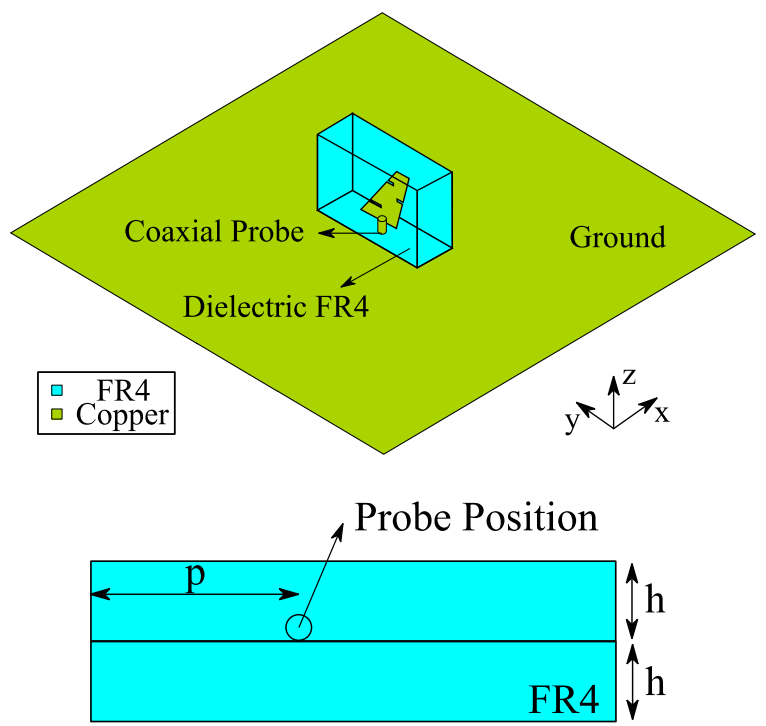

Fig. 2. Model created on HFSS ${ }^{\mathrm{TM}}$ and the superior view of the two FR4 layers attached.

III. PARAMETRIC STUDIES

The HFSS ${ }^{\mathrm{TM}}$ was used to optimize the antenna dimensions starting from the geometry presented in Fig. 1. Initially, the radiator length started in $h_{a}=0.125 \lambda_{0}$ [7], however this length was not producing the best impedance matching at $4.97 \mathrm{GHz}$. Then, the length was adjusted to $0.156 \lambda_{0}$ to get the best antenna performance.

The parametric analysis was focused on the search for the best impedance matching considering the reflection coefficient magnitude.

Next, it is described the influence of the project variables, and the search for optimal antenna dimensions to construct a prototype compliant with the specifications.

A. Influence of $x_{a}$ and $x_{b}$ on antenna parametric analysis

In this section, the dimensions $x_{\mathrm{a}}$ and $\mathrm{x}_{\mathrm{b}}$ exhibited on Fig. 1 are evaluated. The Figs. 3 and 4 show how the reflection coefficient magnitude is affected with $x_{a}$ and $x_{b}$ changes. In this analysis, while $x_{a}$ was changed, $x_{b}, h_{a}, p_{\text {sup }}, p_{\text {inf }}, p_{c}$, gap and $a_{c}$ were kept unchanged, and while $x_{b}$ was changed, $x_{a}, h_{a}$, $\mathrm{p}_{\text {sup }}, \mathrm{p}_{\text {inf }}, \mathrm{p}_{\mathrm{c}}$, gap and $\mathrm{a}_{\mathrm{c}}$ were kept unchanged. 


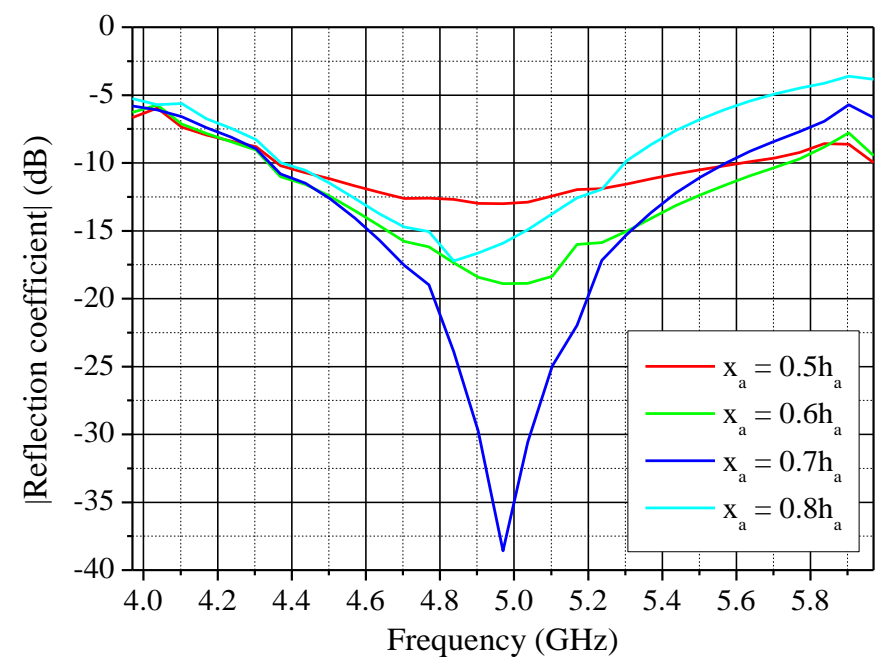

Fig. 3. Reflection coefficient magnitude with $\mathrm{x}_{\mathrm{a}}$ variation.

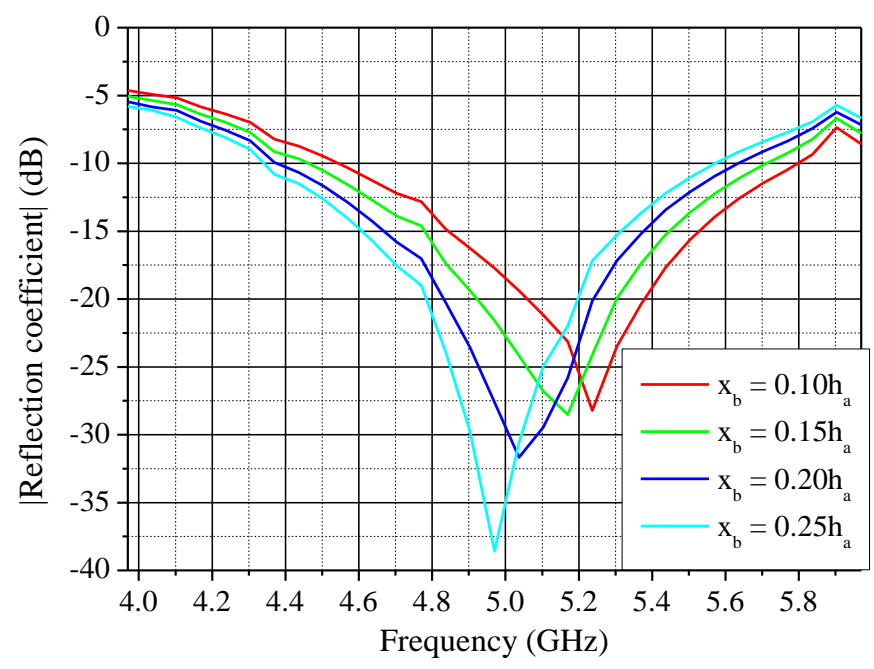

Fig. 4. Reflection coefficient magnitude with $\mathrm{x}_{\mathrm{b}}$ variation.

A $\mathrm{x}_{\mathrm{a}}$ variation caused a more pronounced degradation in the reflection coefficient magnitude, as depicted in Fig. 3, while $x_{b}$ variation resulted in a shifting in frequency, as can be seen in Fig. 4.

Analyzing the operating frequency, the value $x_{a}$ shall be equal to $0.7 h_{a}$. Considering the new value for $\mathrm{x}_{\mathrm{a}}$ the value for $\mathrm{x}_{\mathrm{b}}$, which presented best impedance matching, shall be $0.25 \mathrm{~h}_{\mathrm{a}}$.

\section{B. Gap influence}

The Fig. 5 demonstrates how the reflection coefficient magnitude is changed with the gap variation. It is possible to observe that a gap variation affects the impedance matching, as well as, a frequency shifting. The gap $=1 \mathrm{~mm}$ produced the best impedance matching. 


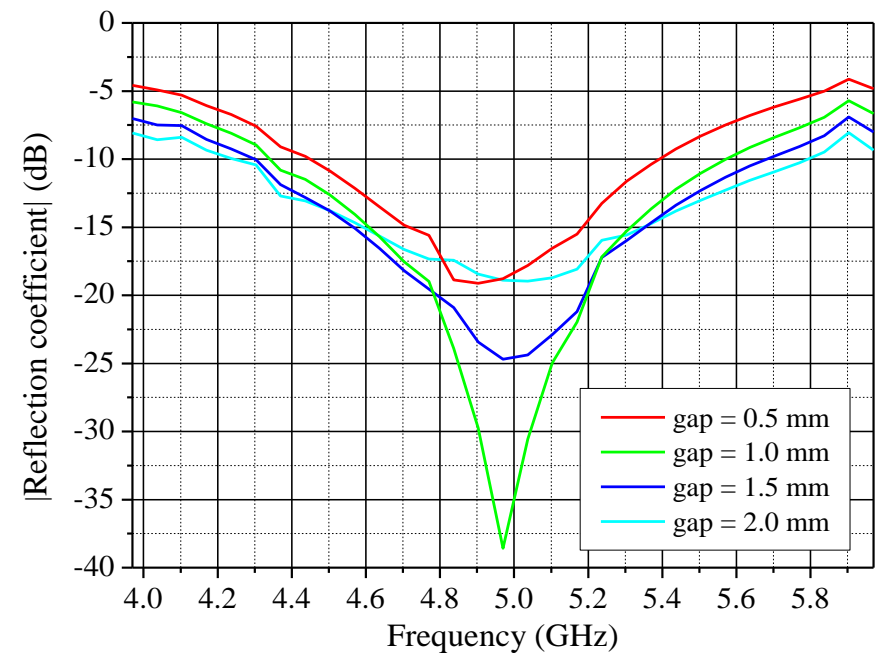

Fig. 5. Reflection coefficient magnitude with gap variation.

\section{Probe position influence}

The Fig. 6 provides a view of how the reflection coefficient magnitude is affected with the probe position $(p)$ variation.

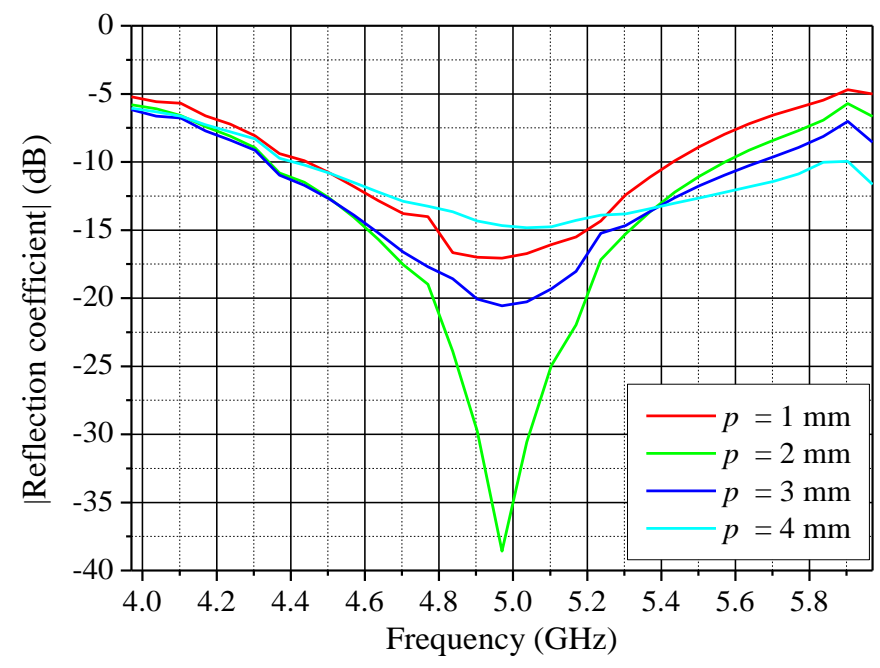

Fig. 6. Reflection coefficient magnitude with probe position variation.

Similar to the gap variation, a probe position change also affects the impedance matching. The probe position which resulted in the best impedance matching was $p=2 \mathrm{~mm}$.

\section{Slots width influence}

The Fig.7 depicts the change on the reflection coefficient with slots width variation $\left(\mathrm{a}_{\mathrm{c}}\right)$.

Considering the frequency of operation, the slot width which produced the best impedance matching was $\mathrm{a}_{\mathrm{c}}=0.4 \mathrm{~mm}$. 


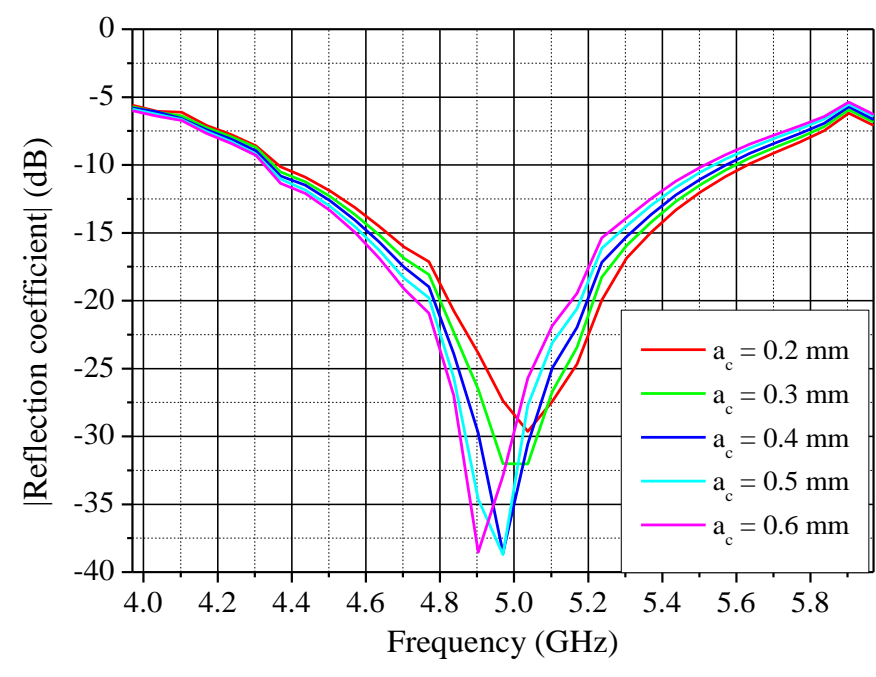

Fig. 7. Reflection coefficient magnitude with slots width variation.

\section{E. Radome influence}

In this case, the analysis was performed with and without radome. As presented on the Fig. 8 the inclusion of the radome decreases the bandwidth, while the radome absence produces more bandwidth with frequency shifting.

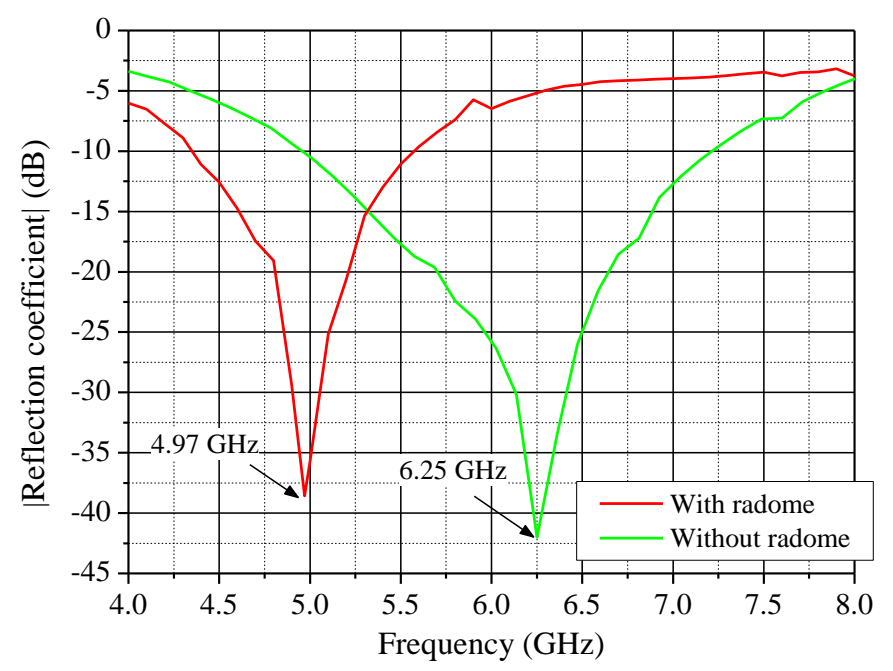

Fig. 8. Reflection coefficient magnitude with and without radome.

\section{F. Ground plan influence}

The Fig. 9 shows the behavior of reflection coefficient magnitude with variation of ground plan area (A). It was observed that as bigger as the ground plan area becomes, the coefficient magnitude increases to below of $-30 \mathrm{~dB}$, at operating frequency. The ground plan contribution is insignificant on the reflection coefficient magnitude. 


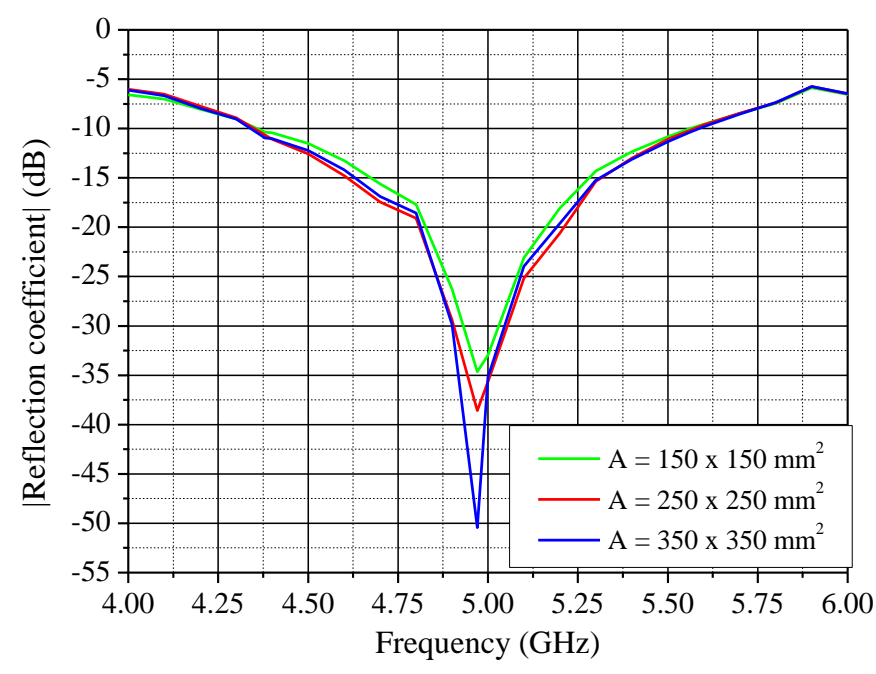

Fig. 9. Reflection coefficient magnitude with ground plan variation.

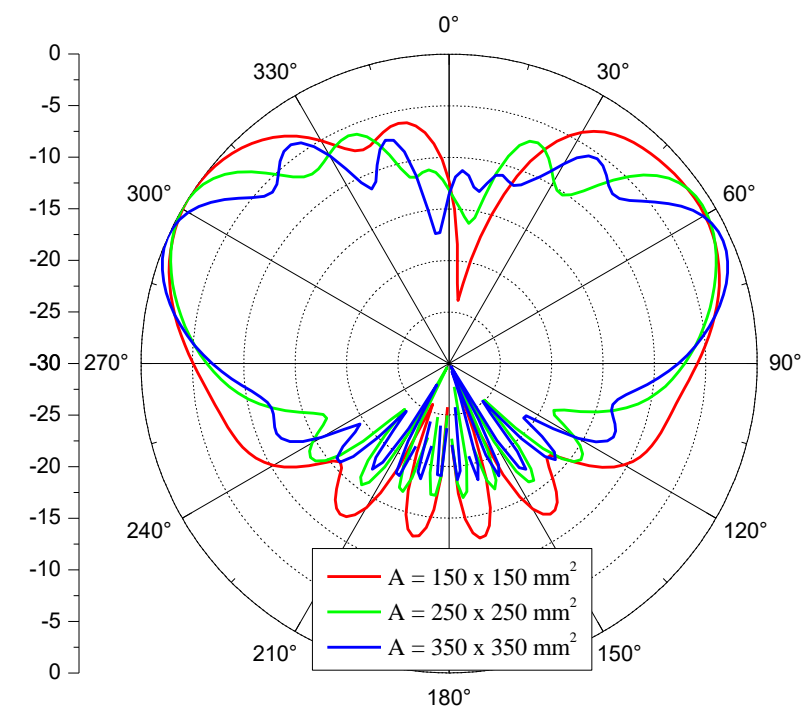

Fig. 10. Radiation pattern in $y z$ plane with ground plan variation.

It was verified considerable changes in the radiation pattern in function of ground plan variation as can be seen on the plot of $y z$ plane at Fig. 10. It was perceived a reduction of back lobe radiation patterns as the ground dimensions was increased.

\section{BLADE ANTENNA ON CYLINDER}

The analysis of a blade antenna on metallic cylinder representing an airframe of aircraft is the scope on this section. It is important to emphasize that computational solution takes considerable time and consumes a lot of RAM memory when it is necessary to simulate antenna on large electrical structure, like an airframe. Therefore, to reduce simulation time keeping accurate results, the hybrid method (FEM-MoM) was applied.

To consider the cylinder effects on antenna radiation characteristics using HFSS ${ }^{\mathrm{TM}}$ hybrid method, it was necessary assembly antenna/cylinder as depicted on Fig. 11, where antenna was covered with an air box type FE-BI boundary, while the metallic cylinder was defined as IE (Integral Equation) Region. 


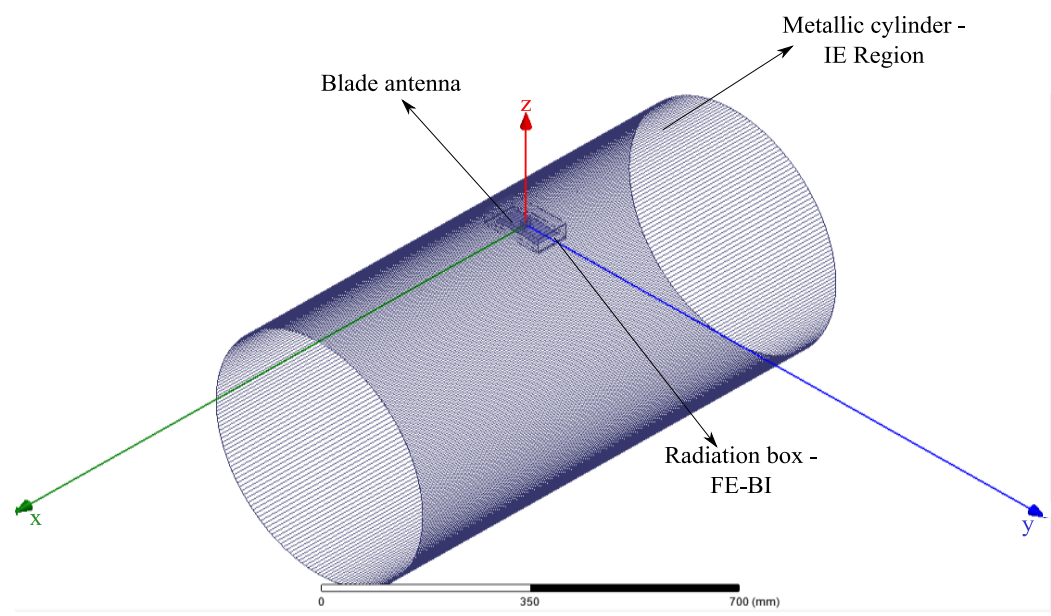

Fig. 11. Blade antenna on metallic cylinder at $\operatorname{HFSS}^{\mathrm{TM}}$.

Comparisons between conventional method (FEM) and hybrid method are illustrated through the graphics of reflection coefficient magnitude, input impedance and radiation patterns in the Fig. 12 and Fig.13.

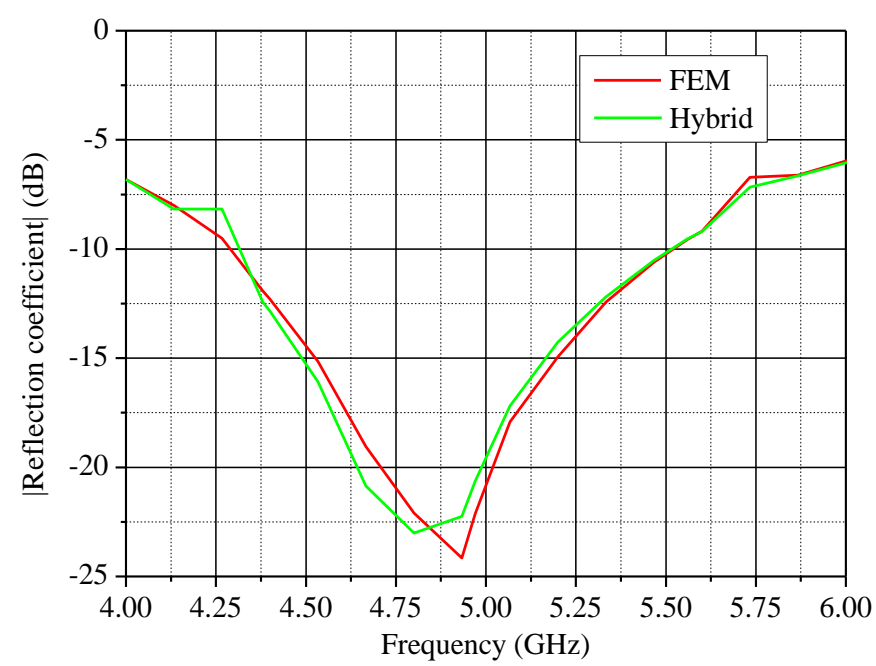

Fig. 12. Comparison the results of reflection coefficient magnitude for different numerical methods.

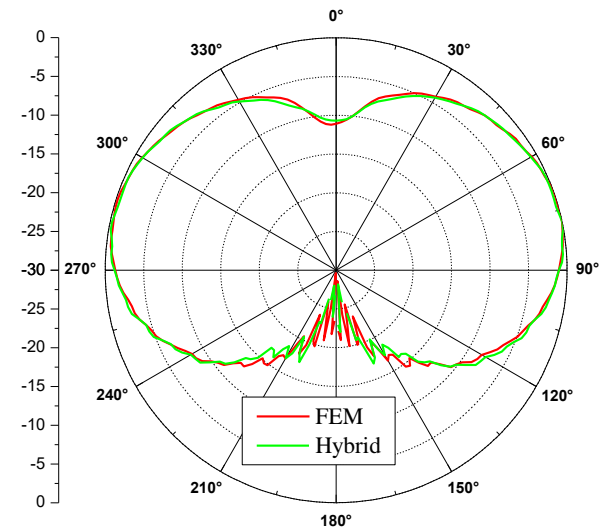

(a)

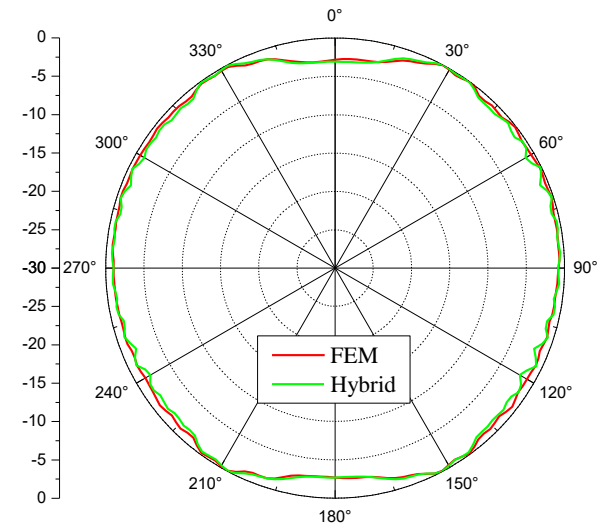

(b)

Fig. 13. Comparison of radiation patterns at $y z$ plane (a) and $x y$ plane (b) using different numerical methods. 
The main antenna figures-of-merit do not differentiate substantially when compared both numerical methods.

The simulations were performed on Xenon ${ }^{\circledR}$ computer with 192 G RAM and clock $2.4 \mathrm{GHz}$, with 5 steps of convergence and 38 points, and in the interval of 4 to $8 \mathrm{GHz}$. The comparison between these numerical techniques considering simulation time and RAM memory usage is shown on Tab. I.

TABLE I. COMPARISON OF NUMERICAL METHODS FOR THE BLADE ANTENNA ON AIRFRAME.

\begin{tabular}{ccc}
\hline Resource & Hybrid & FEM \\
\hline Time & 1,176 minutes & 2,490 minutes \\
RAM memory & $3.6 \mathrm{G}$ & $4.5 \mathrm{G}$ \\
\hline
\end{tabular}

It was observed a reduction of $20 \%$ in RAM utilization while the simulation time became almost twice faster when used the hybrid method.

\section{PROTOTYPE}

After finished the parametric studies, the optimal antenna dimensions for a best impedance matching were those values shown in Tab. II.

TABLE II. VALUES OF THE BLADE ANTENNA

\begin{tabular}{cc}
\hline Parameter & Value \\
\hline $\mathrm{h}_{\mathrm{a}}$ & $0.156 \lambda_{0}$ \\
$\mathrm{x}_{\mathrm{a}}$ & $0.7 \mathrm{~h}_{\mathrm{a}}$ \\
$\mathrm{x}_{\mathrm{b}}$ & $0.25 \mathrm{~h}_{\mathrm{a}}$ \\
$\mathrm{p}_{\mathrm{c}}$ & $1 \mathrm{~mm}$ \\
$\mathrm{p}_{\text {inf }}$ & $10 \mathrm{~mm}$ \\
$\mathrm{p}_{\text {sup }}$ & $2 \mathrm{~mm}$ \\
$\mathrm{p}$ & $2 \mathrm{~mm}$ \\
$\mathrm{gap}$ & $1 \mathrm{~mm}$ \\
$\mathrm{a}_{\mathrm{c}}$ & $0.4 \mathrm{~mm}$ \\
\hline
\end{tabular}

Using the Prototype System Quick Circuits available at LAP/ITA, the pieces of antenna were manufactured, as evidenced by the Fig. 14: FR4 layers (one with radiator element and other as protection) and a supporting plate.

To support the FR4 layers and coaxial probe, it was used a plate of Arlon CuClad $\left(\varepsilon_{\mathrm{r}}=2.55, \tan \delta=\right.$ 0.0018 ) with thickness of $0.762 \mathrm{~mm}$. To short-circuit the inferior and superior faces and to avoid wave guiding were inserted pins, as displayed on the Fig. 14. Although the plate is supporting the layers, it is working as small ground plane as well. 


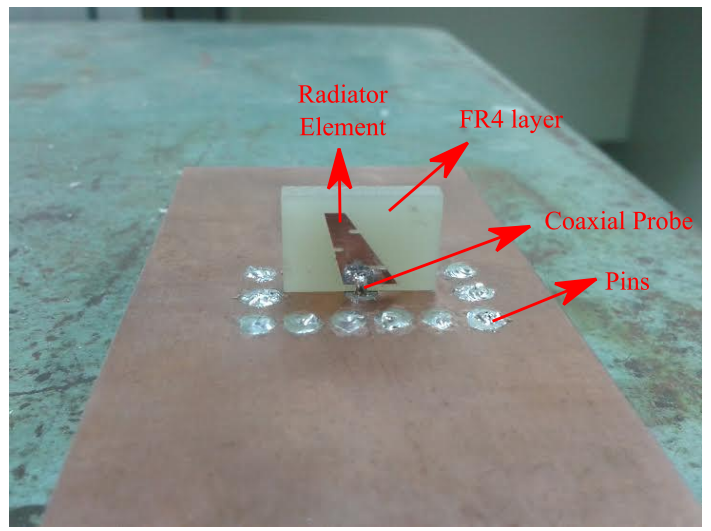

(a)

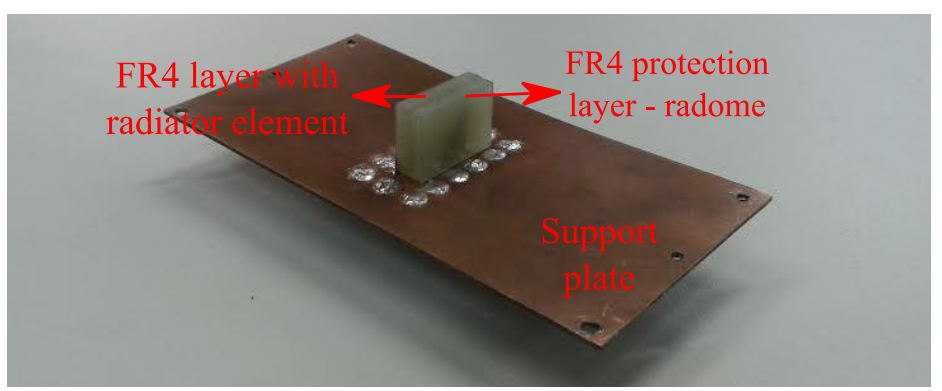

(b)

Fig. 14. Prototype without radome (a) and with radome (b).

Then, the two FR4 layers were glued to construct the radome, but having precautions for not deposit material on the radiator element. Measurements on the prototype were carried out to examine the reflection coefficient magnitude, as well as, comparison with simulated model. These results can be seen in the Fig. 15.

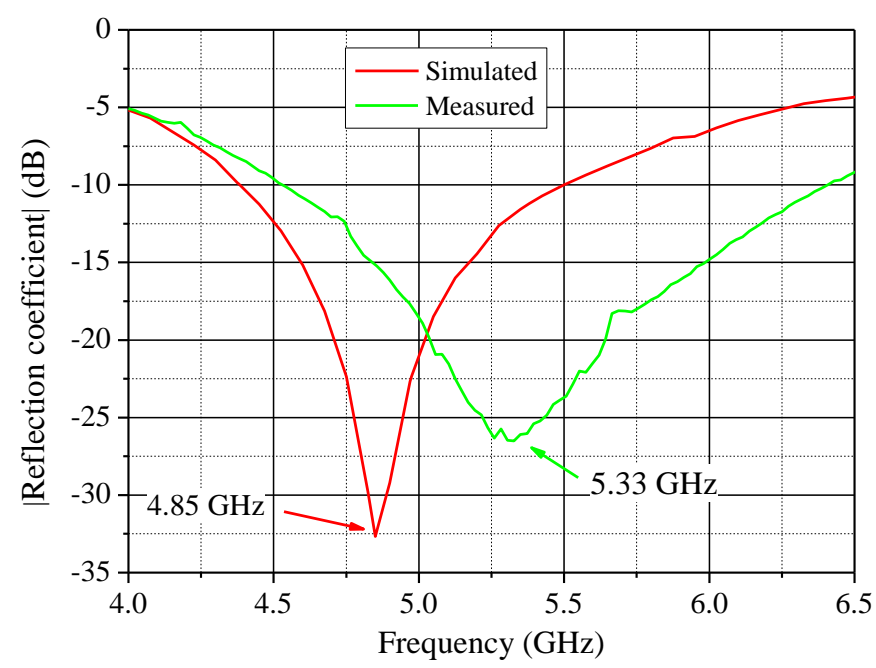

Fig. 15. Comparison of reflection coefficient magnitude for theoretical and prototype models.

The difference raised through the Fig. 15 is associated with variation of electrical permittivity of the substrate (FR4) according [11, 12], or the presence of air between the dielectric layers. Both suppositions can be verified through the parametric studies on HFSS ${ }^{\mathrm{TM}}$. 


\section{A. Electrical permittivity variation}

The Fig. 13 displays the variation of reflection coefficient with electrical permittivity of FR4.

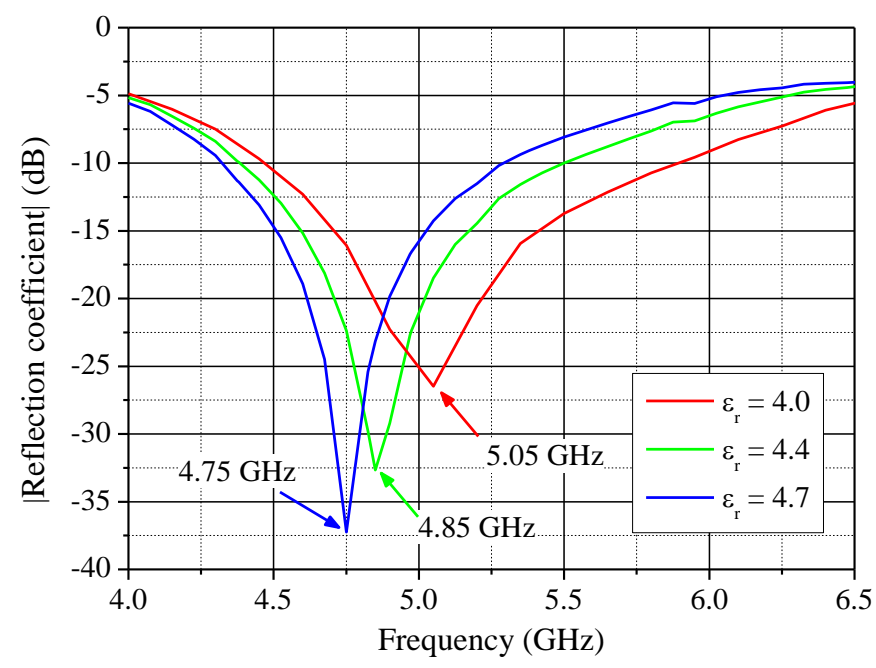

Fig. 16. Comparison of reflection coefficient magnitude with variation of FR4 permittivity.

Based on the graphic interpretation it is evidenced a frequency shifting to higher values when FR4 with lower electrical permittivity are used.

\section{B. Space between layers}

The method used to join the two FR4 dielectric layers and to solder the probe on the radiator element resulted in air between the layers. Thus, aiming to analyze what could be the effects of this gap of air in the input impedance, it was held an experiment with this air gap variation looking its influence on the reflection coefficient. The results are presented on the Fig. 17, for antenna with the ground plan illustrated in the Fig. 14.

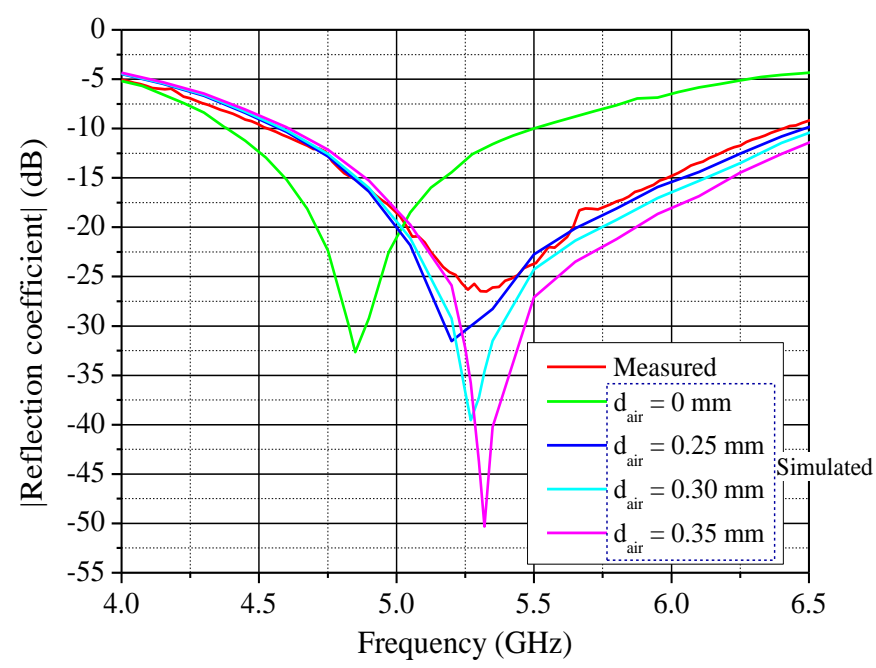

Fig. 17. Comparison of reflection coefficient magnitude with gap variation between the dielectric layers.

Looking the results on the Fig. 17, it is possible to say that the air gap increase moves the center frequency to higher values that the value specified on the requirement.

Considering the antenna with ground plan $\left(\mathrm{A}=250 \times 250 \mathrm{~mm}^{2}\right)$ and space between the FR4 layers $\left(\varepsilon_{\mathrm{r}}=4.4\right)$ of $0.35 \mathrm{~mm}$, measurements on theoretical and prototype models were executed and the 
results are presented in the Fig 18 for a graphic of reflection coefficient magnitude versus normalized frequency. Where $f_{0}$ represents the frequency used to normalize.

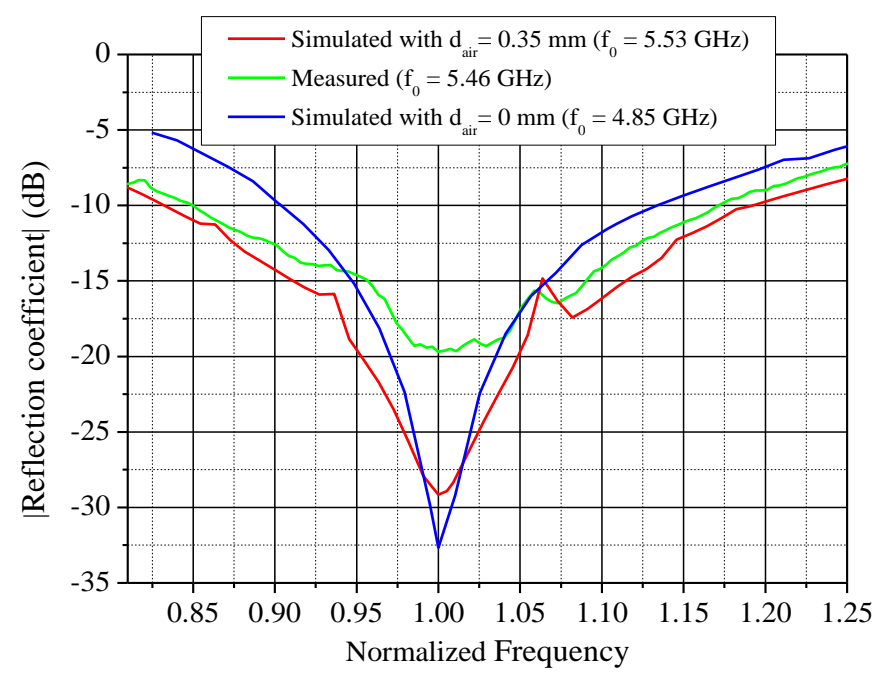

Fig. 18. Comparison of the reflection coefficient magnitude for experimental and theoretical models when the antenna is on large ground.

It is observed that the prototype presents an impedance bandwidth nearly $1.82 \mathrm{GHz}(-10 \mathrm{~dB}$ return loss condition), representing $33 \%$ in relation to the best impedance matching.

The last comparison is the antenna blade prototype in a ground plane cylindrical, shown in Fig. 19. This is a hollow metallic cylinder with $250 \mathrm{~mm}$ of radius. The antenna was fixed on the center of cylinder.

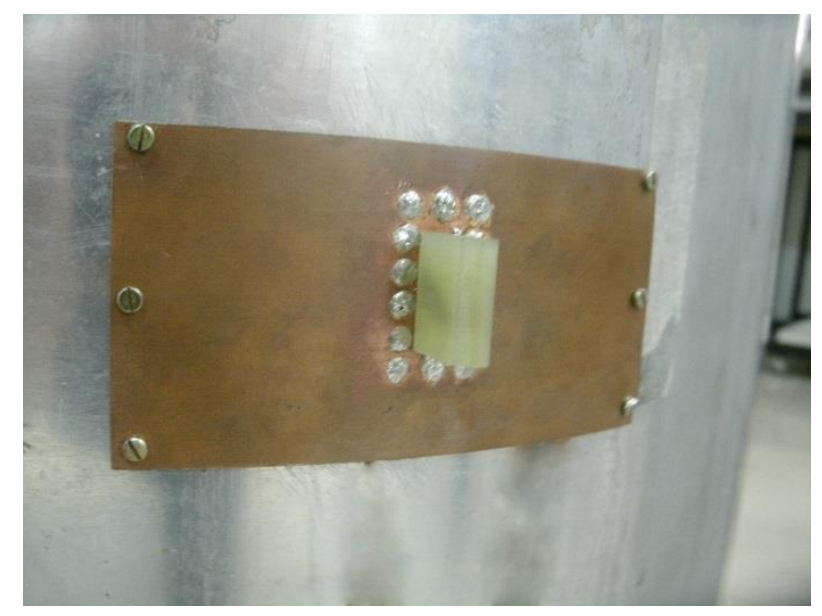

Fig. 19. Prototype of blade antenna on metallic cylinder.

The results of reflection coefficient magnitude for experimental and theoretical models are presented in the Fig. 20. In this case, it was considered FR4 relative electric permittivity $\varepsilon_{\mathrm{r}}=4.4$ and gap $d_{\text {air }}=0.35 \mathrm{~mm}$. 


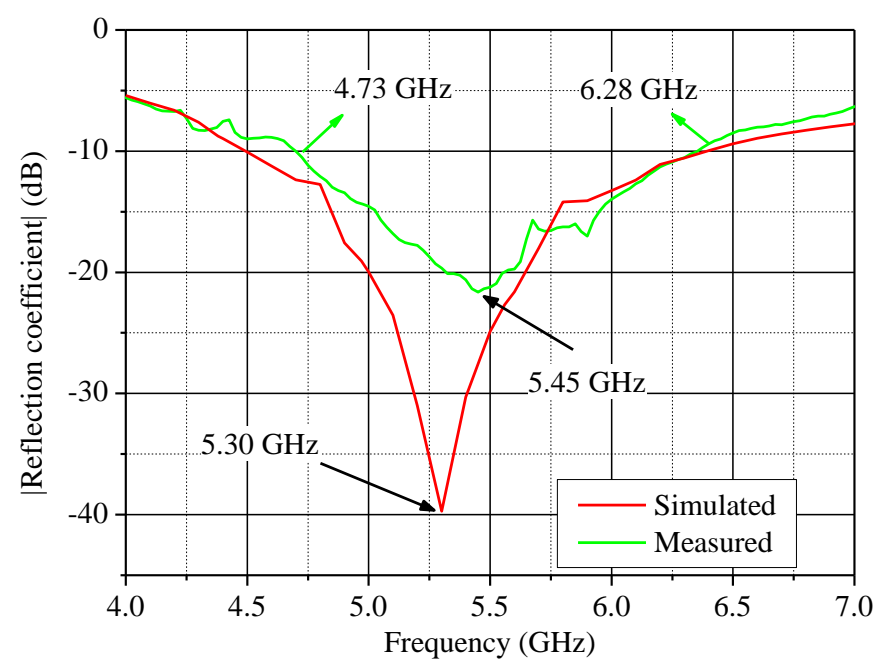

Fig. 20. Comparison of reflection coefficient magnitude for theoretical and prototype models of antenna on metallic cylinder.

The results presented a difference of $150 \mathrm{MHz}$ between the points of best matching. However, in terms of impedance bandwidth, they are practically the same and the best point of matching is bellow $-20 \mathrm{~dB}$, for both cases. Checking the results obtained against the requirements of TCAS, the impedance bandwidth complies with it is necessary to the service.

Using scaling process, it was achieved a bandwidth of $370 \mathrm{MHz}$, which satisfies the bandwidth specification for TCAS. However, the lower frequencies of TCAS service are out of the bandwidth achieved on Fig. 20. Therefore, the antenna optimization is necessary on the cylindrical ground plan to attend all requirements.

\section{CONCLUSION}

In this work, it was demonstrated how the parameters to construct an antenna can influence on the reflection coefficient magnitude. It is also shown that a ground plan variation produced impacts on the radiation patterns of the $y z$ plane.

Measurements on prototype revealed divergences in reflection coefficient magnitude when compared experimental and theoretical models. These divergences are due to variation of FR4 relative electrical permittivity and/or the space created between the layers in function of solder or glue accumulation. However, taking these factors to the simulation scenario is possible to see a theoretical model behaving as the prototype.

Thus, improving the construction techniques for the feeder and measuring the permittivity of FR4, is possible to build a prototype operating in the design frequency.

The impedance bandwidth achieved for the blade antenna on cylinder was nearly $31.2 \%$ while the impedance bandwidth of TCAS is $23.8 \%$.

It was verified by simulations that hybrid method (FEM-MoM) is the best choice to analyze structures electrically large, besides that, the simulation time reduced in twice when compares with the conventional method (FEM) and it was spent $20 \%$ less of RAM memory. Considering the executed simulation with a cylinder representing an airframe, the hybrid technique showed to be 
advantageous over the conventional technique in terms of resource consumption. In the simulation with more complete aircraft with engines and wings, this advantage tends to be much more pronounced in favor of hybrid technique.

\section{ACKNOWLEDGMENT}

The authors would like to thank CNPq for sponsoring project no. 131461/2014-1.

\section{REFERENCES}

[1] Macnamara, T. Introduction To Antenna Placement And Installation. Chichester, West Sussex, U.K.: Wiley, 2010.

[2] Balanis, C. A. Antenna Theory: Analysis and Design, $3^{\text {nd }}$, New York: John Wiley \& Sons Ltd., 2005.

[3] Kumar, Girish, and K. P Ray. Broadband Microstrip Antennas. Boston: Artech House, 2003. Print.

[4] Nair, R. U.; Jha, R. M. Electromagnetic Design and Performance Analysis of Airbone Radomes: Trends and Perspectives [Antenna Applications Corner]. IEEE Antennas and Propagation Magazine. v. 56, p. 276 - 298, Ago 2014.

[5] Sensor system, Inc., Data sheet: L-Band S65-5366- Series, 2004.

[6] SANTOS, Tiago Pereira. Análise de Monopolos Faixa Larga utilizados em Aeronaves. 2015. 98f. Dissertação (Mestrado em Engenharia Aeronáutica e Mecânica) - Instituto Tecnológico de Aeronáutica, São José dos Campos.

[7] Ono, M.; Takeichi, T. A One-Eighth-Wave Blade Antenna With Metal Leading Edge. 1974. IEEE Antennas and Propagation Society International Symposium. v. 12, p. 225 - 228, Jun 1974.

[8] Yan, Y. Zhao, LIANG, C. H. Analysis of wire antenna around dielectric or coated object using parallel MoM-PO technique. IET International Radar Conference 2013. P. 1 - 6, Apr 2013.

[9] LIU, Z. L.; WANG, C. F. An efficient iterative MoM-PO hybrid method for analysis of an onboard wire antenna array on a large-scale platform above an infinite ground. IEEE Antennas and Propagation Magazine. v. 55, n. 6, p. 69 - 78, Dez 2013.

[10] BECKER, A., HANSEN, V. Hybrid ${ }^{(3)}$ : combining the time-domain method of moments, the time-domain geometrical theory of diffraction and the FDTD. IEEE Antennas and Propagation Society International Symposium. v. 2A, p. $94-$ 97, Jul 2005.

[11] Ammann, M. A. Comparasion of Some Low Cost Laminates for Antennas Operating in the 2,4 GHz ISM Band. IEE Colloquium on Low Cost Antenna Technology. v. 3, p. 1 - 3, London, 1998.

[12] NASCIMENTO, D. C., Antenas para Comunicações Móveis. 2007.169f. Tese (Mestrado em Engenharia Eletrônica e Computação) - Instituto Tecnológico de Aeronáutica, São José dos Campos. 